\title{
The 'Downside' of Women Empowerment in India: An Experimental Inquiry into the Role of Expectations
}

\author{
Luuk van Kempen
}

Accepted: 5 January 2009/Published online: 16 January 2009

(C) The Author(s) 2009. This article is published with open access at Springerlink.com

\begin{abstract}
The paper reports on a field experiment conducted among poor women organized in self-help groups in the north-east of India. The experiment tests in a simple game whether overly optimistic expectations with respect to the benefits of exercising agency reduces one's appreciation of remaining with agency in the future. If so, unrealistic expectations may trigger behaviour that jeopardizes empowerment processes. It is hypothesized that negative emotions, such as disappointment, bring about such risks. We find that overstretched expectations may indeed work against empowerment if the gap between achieved and expected outcomes following increased agency is sufficiently wide. However, modest expectation gaps have the opposite effect and tend to promote attitudes conducive to empowerment. A tentative explanation for this result is offered by combining insights from recent work on the role of aspirations.
\end{abstract}

Keywords Empowerment $\cdot$ Subjective well-being $\cdot$ Expectations

\section{Introduction}

The current debate on what constitutes well-being is dominated by the controversy between the capability approach on the one hand and the happiness or subjective wellbeing (SWB) approach on the other. A forceful argument to prioritize capabilities rather than subjective well-being is the alleged malleability of the latter. In the context of poverty, it is often argued that the poor manage to adapt to their material deprivation by adjusting aspirations and desires downwards. Empirical studies lend some support to this 'hedonic adaptation' argument, as documented in Clark (2007, p. 6). For instance, Biswas-Diener and Diener (2001) find that poor slum dwellers in Kolkata do not report significantly lower general life satisfaction than a more affluent control group in the same city. Survey data from South Africa also reveal at least partial adaptation to income poverty and low

L. van Kempen $(\bowtie)$

Centre for International Development Issues Nijmegen (CIDIN), Radboud University,

Nijmegen, The Netherlands

e-mail: 1.vankempen@maw.ru.nl 
educational performance (Barr and Clark 2007). This human ability to come to terms with one's deprivation may partly explain why development researchers have been reluctant, with some notable exceptions, ${ }^{1}$ to embrace the SWB approach, and have invested in the operationalization of Sen's idea of capabilities instead. A clear illustration is the rise to prominence of the concept of empowerment in development circles. Viewed as the "expansion in people's ability to make strategic life choices in a context where this ability was previously denied to them" (cf. Kabeer 1999, p. 437), empowerment is conceptually very close to enhancing capabilities, which aims to expand people's freedom to live the life that one values. ${ }^{2}$

Adoption of empowerment as the central development objective does not imply, however, that SWB can be safely ignored. While SWB may adapt to one's capability set, the empowerment process at the same time is responsive to people's SWB. Diener and Biswas-Diener (2005) argue that emotional well-being determines in part the success of psychological empowerment processes. The authors warn that "negative emotions can stop the cycle of psychological empowerment" (pp. 5-6). If the aim is to generate self-sustaining empowerment processes, this warning calls for the identification of features of development initiatives that may jeopardize the SWB of its participants in an early stage. While few evaluation studies of development programs consider well-being as an explicit indicator of success or failure, evidence is available for one of the most popular and celebrated interventions aimed at empowerment, i.e., micro-credit provision to women's groups. While this is sometimes used as a mere poverty alleviation tool, the income generated by group lending to poor women is generally regarded as an instrument towards the broader goal of transferring decision-making power into the hands of women. Economic empowerment is assumed to spill over to the social and psychological domain. ${ }^{3}$

Ahmed et al. (2001) compare self-reports of emotional well-being between Bangladeshi women participating in a micro-credit scheme of BRAC, a well-known non-governmental organization, and non-participating women. On the basis of a survey covering 198 BRAC and 1,169 non-BRAC households, the authors find that the higher a women's perceived contribution to household income, the more likely, ceteris paribus, she is to report emotional stress. This not only leads to the result that BRAC women fail to show less emotional stress than their non-BRAC counterparts, it also shows that BRAC-women who are more effective in using micro-credit to generate household income are more emotionally stressed than BRAC-women who perform poorly in this respect. Interestingly, it is especially during the first 3 years of participation in BRAC that emotional stress increases, which leads the authors to argue that "by promoting women's involvement in household income generation, emotional stress is provoked among new recipients" (Ahmed et al. 2001, p. 1964). This negative effect on SWB of early empowerment seems to have translated into behavioural attitudes that go against the spirit of empowerment as well. When asked about their responses to emotional stress, BRAC-members "were more likely to adopt a fatalistic or resigned attitude than non-members, whether poor or better-off" (ibid., p. 1962).

The authors put forward two factors that may be important in bringing about these intriguing results. First, the defiance and transgression of traditional gender roles in a

\footnotetext{
${ }^{1}$ See e.g. Rojas (2008) and Guillen-Royo (2008) for poverty analyses using a subjective well-being approach for Mexico and Peru, respectively.

2 See Stern et al. (2005, p. 103) and Alsop et al. (2006, pp. 15-16) for explicit acknowledgement of the similarity between the concept of empowerment and Sen's capabilities approach.

${ }^{3}$ Some authors contest the empowerment potential of micro-credit programmes. See Kabeer (2001) for an overview and analysis of the debate.
} 
patriarchal social set-up may create anxieties and tensions for starting female entrepreneurs. Second, and this is a less obvious one, the negative impact on SWB may be due to the "discrepancy between expectations and achievement" (p. 1957). The researchers seem to refer to the idea in psychology that "initial improvements may produce expectations of future improvements and create frustration when the anticipated improvements do not occur or are not realized quickly enough" (Frederick and Loewenstein 1999, p. 308). While the supposition of overly optimistic expectations is not further substantiated in the paper, we take interest in the question whether this could indeed negatively impact on SWB such that it generates behaviour that works against empowerment. Hence, the question we aim to address in the current paper is whether expectation shortfalls entail the risk of bringing the empowerment process to a halt within the context of the empowerment of women living in poor and traditional societies.

Ideally, one would like to analyze this potential problem in a longitudinal study, where women participating in a certain empowerment initiative are periodically asked for their expectations, their emotional well-being and their achievements on a set of empowerment indicators to detect how these interlink over time. The hypothesis would be that those individuals who start out with very high expectations, all other things equal, report lower SWB in the process and end up being less empowered. In order to perform a preliminary test of this hypothesis, we take a shortcut by mimicking part of the empowerment process in a simple game. Our ambition in doing so does not extend beyond indicating whether it would be worthwhile to undertake a longitudinal study that addresses the question at hand in a more realistic setting than the experimental one designed here.

The game, which consists of three stages, aims to capture the essential feature of empowerment, i.e., enhanced freedom to make one's own strategic choices (enhanced agency). The first stage features a scenario where participants do not have any control over their strategy in the game, whereas they gain full control over it in a second stage. After playing this second stage, each participant casts a vote to indicate whether she prefers to play the third stage with or without control over one's strategy. Since the voting options are such that expected payoffs in the third stage are roughly similar across both scenarios, the participant's vote is taken to reflect her propensity to give up the freedom to determine her own strategy. While obviously very stylized, we believe the simplicity of the game is at the same time a merit. Since the success of women empowerment initiatives likely hinges on a myriad of factors (such as the attitude of male family members), using the field as a 'laboratory' rules out at least some of these, which might otherwise obscure a potential effect from expectations or, more generally, what psychologists refer to as 'feedforward' processes.

Unfortunately, the experimental gaming method does not lend itself easily to a simulation of the negative emotions that are believed to stem from unmet expectations. The duration of the game is too short for frustration to build up. Participants are therefore unlikely to report the types of emotional stress that are experienced by the women in Ahmed et al. (2001) and Omorodion (2007). Nonetheless, we believe that the fact that the game is played with real stakes may invoke sufficient disappointment in participants to trigger behavioural reactions. While focusing in the results section on these behavioural responses, an effort will be made to make a connection with levels of subjective well-being.

The experiment was conducted with female members of self-help credit and savings groups in India's north-eastern state of Orissa. Some background on the research location,

\footnotetext{
${ }^{4}$ Omorodion (2007) also hints at unrealistic expectations as a contributing factor to emotional stress (e.g. depression, high blood pressure and withdrawal syndrome) among female members of micro-credit groups in Nigeria.
} 
with special emphasis on women's status, is provided in Sect. 2. The details of the experiment, which we believe is novel in its set-up, are described in Sect. 3. Section 4 presents the results, followed by an interpretation of these in Sect. 5, which draws heavily on the notion of aspirations. Finally, Sect. 6 concludes.

\section{Women Empowerment in Orissa}

Orissa is one of the least-developed states in India, featuring the highest income poverty rate in the country, with close to half of the population earning an income below the poverty line (Government of Orissa 2004, pp. 20-21). Non-income development indicators for this state also tend to fall short of the all-India average by a substantial margin. For example, life expectancy at birth is much lower for both men and women (see Table 1). The fact that the difference for women $(-7.2$ years) exceeds that for men $(-3.8$ years) is indicative of a relatively high level of gender inequality in Orissa compared to other Indian states.

Within Orissa living conditions and women's status vary substantially across districts. For our field experiment we selected two districts that capture some of this intra-regional variation, i.e., Balangir and Puri. The Balangir district in the state's interior forms part of an area that is considered one of the poorest on the Indian subcontinent (ibid., p. 24). Chronic drought conditions are responsible for high levels of food insecurity and extreme income poverty. Roughly a third of the population is classified as 'very poor'. While Balangir's human development index (HDI) is below the state's average (see Table 1), the coastal district of Puri shows an above-average performance on human development. This notwithstanding, a mixed picture emerges from Table 1 regarding its record on gender bias and women empowerment. Decision-making power in the private sphere is likely to be higher for women in Puri than in Balangir. Whereas more than half of the women in Balangir married before entering (legal) adulthood, this is the case for only one out of every seven women in Puri. Regarding family planning, a lower share of women having a third or higher-order birth is reported for Puri, which points in the same direction.

Although Balangir is generally considered to have a more traditional value orientation concerning gender roles, this does not imply that more developed districts like Puri are not

Table 1 Selected development and gender-inequality indicators: Balangir, Puri and all-Orissa

\begin{tabular}{llll}
\hline & Balangir & Puri & Orissa \\
\hline Human development index (HDI), 2004 & 0.546 & 0.657 & 0.579 \\
Share of population below poverty line & 0.49 & 0.45 & 0.48 \\
Female life expectancy at birth (years), [all-India: 66.9] & NA & NA & 59.7 \\
Male life expectancy at birth (years), [all-India: 63.9] & NA & NA & 60.1 \\
Female infant mortality rate (per 1,000), 1999 & 98 & 75 & 96 \\
Male infant mortality rate (per 1,000), 1999 & 96 & 70 & 97 \\
Sex ratio: females per 1,000 males in 0-6 years age group & 967 & 921 & 950 \\
Female literacy rate (\%) & 39 & 68 & 51 \\
Male literacy rate (\%) & 70 & 0.14 & 76 \\
Share of women married below 18 years of age & 0.58 & 0.37 & 0.36 \\
Share of women having 3rd or higher-order birth & 0.45 & 0.45 \\
\hline
\end{tabular}

Source: Government of Orissa (2004). Data refer to 2001, unless otherwise indicated 
endowed with institutions and norms that discriminate against women. The existing gender bias manifests itself in Puri in an extremely unfavourable female-to-male sex ratio (see Table 1). The Government of Orissa (2004) claims with regard to the alarming figures for Puri and other better-off coastal districts that "better access to sex determination tests through ultrasound and amniocentesis techniques has resulted in female infanticides in large numbers during the early stages of pregnancy". The relatively low prevalence of sexselective abortion in Balangir can partly be explained by limited access to sex determination techniques, but may also be due to the high share of Scheduled Tribes (ST) in its population. Tribal people make up $22 \%$ of Balangir's population against only $3 \%$ of Puri's. While their low status in Orissan society entails high levels of economic deprivation, tribal communities have more equal gender relations compared to communities of Scheduled Castes (SC), Other Backward Classes (OBC) and non-scheduled castes. Dowry-related violence against women, such as dowry homicide and dowry torture, is much less common in tribal than in non-tribal areas of the state, for example (ibid., p. 153).

An attitudinal survey that we carried out in 2008 among 388 randomly selected women from eight rural communities in Balangir (197 respondents) and Puri (191 respondents) sheds additional light on the level of women empowerment in these districts. Before examining selected attitudes, let us first briefly characterise the sample. In terms of marital status, $90 \%$ of the interviewed women are married, $5 \%$ are widowed, and the remaining respondents are either unmarried or divorced. The women in the sample are predominantly Hindu (87\%), while Christians and Muslims represent 9 and $4 \%$ of the total, respectively. Close to $80 \%$ of the interviewed women belong to a disadvantaged social group (ST, SC or OBC), which is reflected in a poor educational profile. Only $20 \%$ has qualifications beyond primary school and more than $40 \%$ has not received any formal education. Half of the surveyed women indicate to be employed at the time of the survey. Within this category, the largest group consists of agricultural wage labourers, followed by waged workers outside agriculture.

Respondents were asked to indicate their level of (dis)agreement with a set of statements on a five-point scale ( $1=$ 'strongly disagree', $5=$ 'strongly agree'), one of which reads as follows: 'I have control over my own life'. About $17 \%$ of the sample disagrees and another $5 \%$ strongly disagrees with this statement. Three-quarters of those who indicate such a lack of agency are part of the Balangir sub-sample. A comparison of the mean scores in the two districts on this item confirms this difference in perceived agency. The average Balangir respondent scores 3.1, which is significantly lower than the average score of 4.3 reported by Puri respondents (Mann-Whitney test; $z=-9.83, P<0.001$ ).

A better understanding of the actual degree of agency that respondents are able to exercise in daily life can be obtained by examining their opinions regarding gender relations. For example, 54\% agrees (of which most even strongly so) to the statement that 'men are entitled to command their women'. Independent decision-making is clearly not the norm, as is also witnessed by the fact that $51 \%$ answers in the negative when asked whether they are able to visit a doctor without asking permission from a male person. In addition, the survey shows substantial tolerance to physical abuse on the part of men. Four out of every ten women condone wife-beating in case the woman has been cheating on her husband and three out of ten believe that women who are experiencing domestic violence tend to have themselves to blame for it. Interestingly, the statement that 'the dowry system is a fair system' meets with little support. Only $15 \%$ of the respondents agree that it is fair, while 58\% strongly disagrees. On the whole, the attitudes of women from Balangir district attest more strongly to a lack of empowerment than those expressed by respondents from Puri. 
The main strategy to empower women in Orissa (as in most parts of India) is through the creation of women self-help groups (SHGs). Although several distinct SHG models exist, savings and credit tend to form the strategy's core component, starting with an initial period of collective savings to facilitate inter-group lending, which over time matures into groups (or clusters of groups) taking larger loans from external parties like banks or donor agencies. SHG models designed by non-governmental organisations (NGOs) tend to complement their facilitating role in the loan and savings programme more substantially with activities that directly aim to promote women's rights to resources, identity, political participation, information and justice than SHG programmes initiated by government agencies (Jakimow and Kilby 2006, p. 381). The relevance of SHGs in the Indian context is witnessed by the fact that "the SHG has become the unit of development intervention, with the majority of programmes aimed at women implemented with existing or newly organised SHGs" (ibid., p. 382). For this reason we also conduct our experiment with SHGs rather than with other possible constellations.

\section{The Field Experiment}

The experiment was conducted in four villages in the Balangir district and six villages in the Puri district in the period February-March $2008 .^{5}$ The villages were selected on the criterion that they should be as representative as possible for their respective districts' rural areas and preferably be included in the aforementioned survey on female attitudes. In total, a number of 15 SHGs, ranging in size from 9 to 11 members, participated in the experimental game. Nine SHGs (93 individuals) were recruited for the game in Balangir and six groups (63 individuals) in Puri. The actual game sessions, which lasted for about an hour per group, were generally organized in public spaces such as a community centre or primary school, but occasionally also in the patio of one of the group members' dwellings. Local research assistants explained the game to the participants in their vernacular, i.e., a dialect of Oriya.

The game consists of three stages. In the first stage participants play a trivial game of chance. Each of them receives seven coins of a particular colour and throws a die to decide how many coins from this endowment are put into a common pot, while keeping the remaining ones. Subsequently, after all participants have put their coins, two coins are randomly drawn from the pot by the experimenter. These are the winning coins that determine the payoff for the entire group. The rules of the game are such that the amount of money that is won (and will later be added to the group's savings account) increases with the number of coins that remain with the owner of a winning coin. Hence, the higher the number that comes up on the die for a particular participant, the higher the probability that one of the randomly selected winning coins will belong to her, but the lower the corresponding payoff. Since the game deals with collective rather than individual payoffs, it is in principle irrelevant whose coins are drawn. What matters is that coins are drawn that are relatively rare in the pot, as this generates the highest payoff for the group. Even though participants cannot influence this and therefore should not care at all to whom the winning coins belong, it is conceivable that participants enjoy some kind of 'warm glow' feeling in case it is one of their own coins that makes a contribution to group savings, given that the colour of one's coins is public knowledge. The game of chance is played for three rounds

\footnotetext{
5 The Balangir villages include Bidighat, Janakpur, Sibthala and Talijarana. In Puri, the experiment was conducted in Bada Sri Mukha, Ghodasalia, Jagiri Tainabad, Juanlo Beheresani, Ratilo and Viligram.
} 
and the respective payoffs are added up and communicated to the participants (see the Appendix for the exact game instructions).

The second stage consists of another three rounds of the same game, but after removing the element of chance. Instead of using a random device to decide how many coins to put in the pot and how many are kept, the participants are now granted the freedom to decide for themselves. The only restriction is that they must put at least one coin and keep at least one. It can easily be seen that the group payoff is maximized when each participant chooses to put only one coin in the pot and remains with six. If the participants manage to coordinate on this Nash-equilibrium, or even with an occasional deviating player, the payoff per round in this 'empowered' condition exceeds that of the first stage. This feature of the experiment captures the idea that taking control over one's actions will generally result in better (pecuniary and/or non-pecuniary) outcomes than when adopting a fatalistic attitude, especially when others do the same and better outcomes require collective action. ${ }^{6}$ Note that the participants are not allowed to discuss the optimal strategy amongst each other, so that they have to rely on their own capacity to solve for it, which may require some learning-by-doing, or infer the best response from imitating others. Again three rounds are played under this set of rules.

The third and final stage consists of either playing two extra rounds of the game as in stage I (by throwing a die) or, alternatively, one extra round as in stage II (own decision). The players in each group decide for one of these two options by simple majority voting. Each player indicates her individual preference by casting an anonymous vote in favour or against reintroducing the chance element. The difference in number of rounds $(2: 1)$ serves to roughly equalize (in expected value terms) the extra group payoff to be obtained in stage III, since a round in which participants make their own decision tends to generate a payoff roughly twice as high on average. Equalizing the expected payoff across the two options allows us to isolate the value that participants attach to being able to control their actions rather than these being governed by fate (or "karma" in the Indian context), regardless of the outcomes that are achieved by these. Put differently, we aim to measure the value of experiencing agency. Following Kabeer (1999), the notion of agency extends beyond the mere freedom to act according to one's own discretion and also includes the sense of agency, which captures "the meaning, motivation and purpose which individuals bring to their activity, [...] or "the power within"” (p. 438).

The hypothesis to be tested is whether the value of having agency declines when the benefits of enhanced decision-making power did not live up to prior expectations. Therefore, participants are requested after stage I to state their expectation regarding the group's total payoff in stage II. In order to provide an incentive to think carefully about this expectation level, participants are told that the individual whose expectation comes closest to the actual payoff will be awarded a small prize. The observed difference between the expected and achieved payoff in stage II (henceforth referred to as 'expectation gap') should be systematically related to the voting behaviour after this stage, since the latter is a proxy for participants' valuation of exercising agency.

In addition to the elicitation of expectations, participants are requested to express their level of satisfaction with their group's payoff after stage I and again after stage II. The aim is to capture potential disappointment with the gains from empowerment in stage II. The experiment concludes by calculating the overall payoff for the group over the three stages of the experiment and handing over the corresponding amount in cash to the secretary of

\footnotetext{
${ }^{6}$ Rowlands (1997), for instance, stresses that overcoming fatalistic attitudes is a key challenge in the empowerment process of poor women in developing countries.
} 


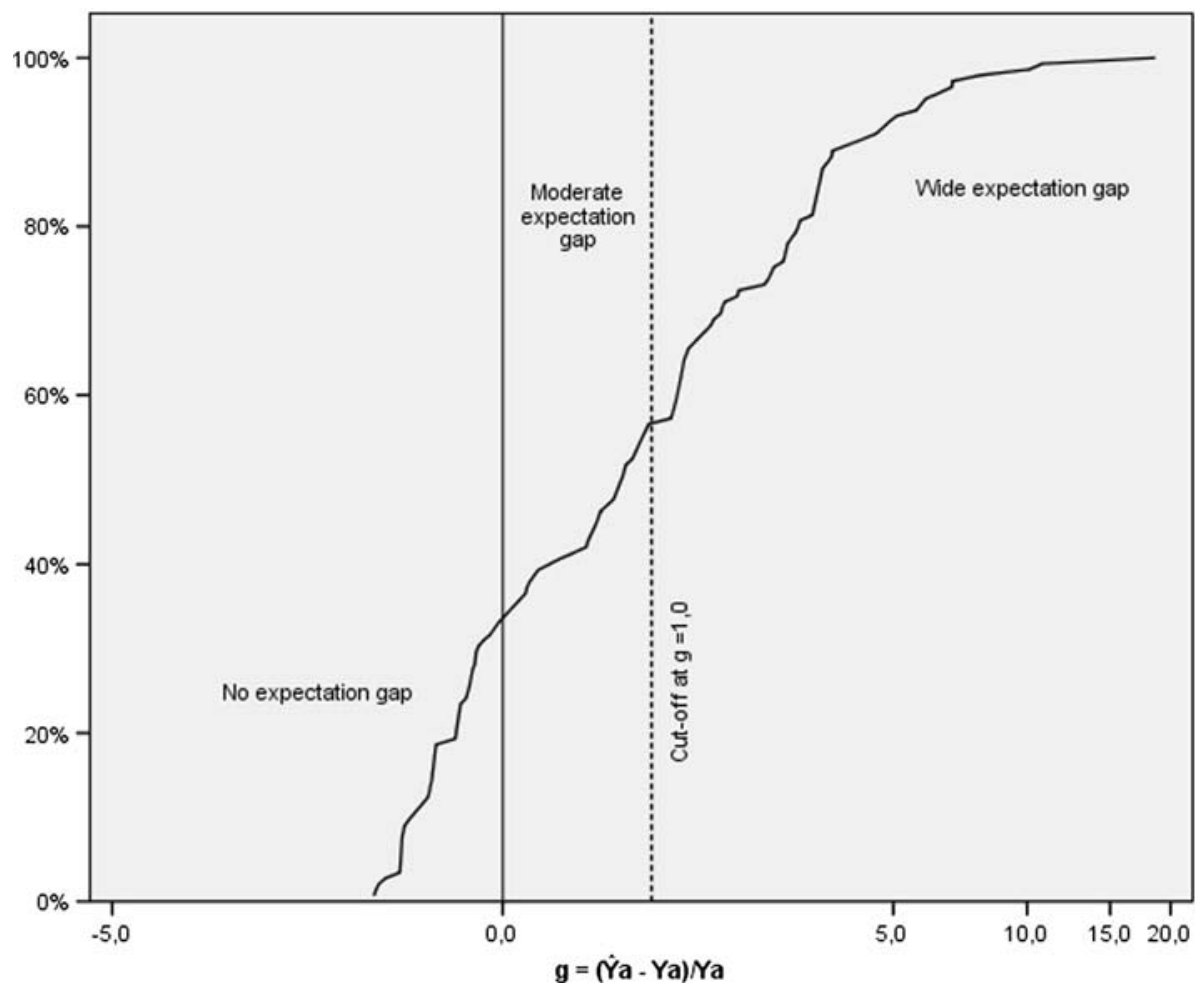

Fig. 1 Cumulative distribution of participants according to expectation gap

the SHG. Total group earnings varied from Rs. 250 to 500, which implied individual earnings in the range of 2-3 international dollars. ${ }^{7}$

\section{Results}

Let us first check to what extent participants' expectation concerning the monetary payoff in the agency condition $\left(\hat{Y}_{\mathrm{A}}\right)$ exceeded the payoff actually achieved by the group under this set of rules $\left(Y_{\mathrm{A}}\right)$, as this is the assumed root of the problem. We define the expectation gap as follows: $g=\left(\hat{Y}_{\mathrm{A}}-Y_{\mathrm{A}}\right) / Y_{\mathrm{A}}$. The distribution of participants over $g$ is depicted in Fig. 1 . Note that the horizontal axis has been rescaled exponentially for presentational purposes.

Expectations turn out to have been too optimistic $(g>0)$ for $69 \%$ of the participants ex post. At the median, the gap equals 0.9 , which implies that the expected payoff exceeds the actual payoff by $90 \%$. For the remainder of the analysis, we subdivide participants with $g>0$ into two groups; those with a 'moderate' expectation gap $(0<g \leq 1)$ and those with a 'wide' gap $(g>1)$. The cut-off point at $g=1$ is arbitrary, but intuitive in the sense that beyond this point the expected payoff is more than twice the actual payoff, which suggests that participants are clearly off the mark. The idea behind the categorization is to set off

7 According to recent World Bank data (2008), \$PPP $1=$ Rs. 14.67. 
this group from the rest, since these participants, who constitute $46.8 \%$ of the sample, form the high-risk group in our hypothesis and therefore warrant special attention.

A preliminary insight into the relation between $g$ and the value that participants attach to having agency after experiencing $g$ can be obtained by comparing the voting behaviour across the three 'expectation gap' categories, as shown in Fig. 2. For the group who did not experience a (positive) expectation gap $(g \leq 0)$, we observe an equal split between votes in favour and against reintroducing the chance element in stage III. Surprisingly, those experiencing a moderate gap are less likely to vote in favour of this zero-agency condition. In line with our hypothesis, however, those facing a wide gap between expectation and achievement are more likely to do so. Over the whole sample, 52\% voted in favour of 'throwing a die' instead of making one's own decision. This resulted in five out of fifteen groups voting in majority to continue in the agency condition and seven groups reverting to the chance game. In two groups the votes were tied.

The pattern in Fig. 2 needs to be interpreted with caution for two reasons. First, different perceptions about which option, the one with or without agency, will generate the highest monetary payoff may have emerged across groups due to idiosyncratic game-play. While the options were designed such that expected payoffs should be roughly equal, there is no guarantee that participants held this perception, especially in groups where outcomes

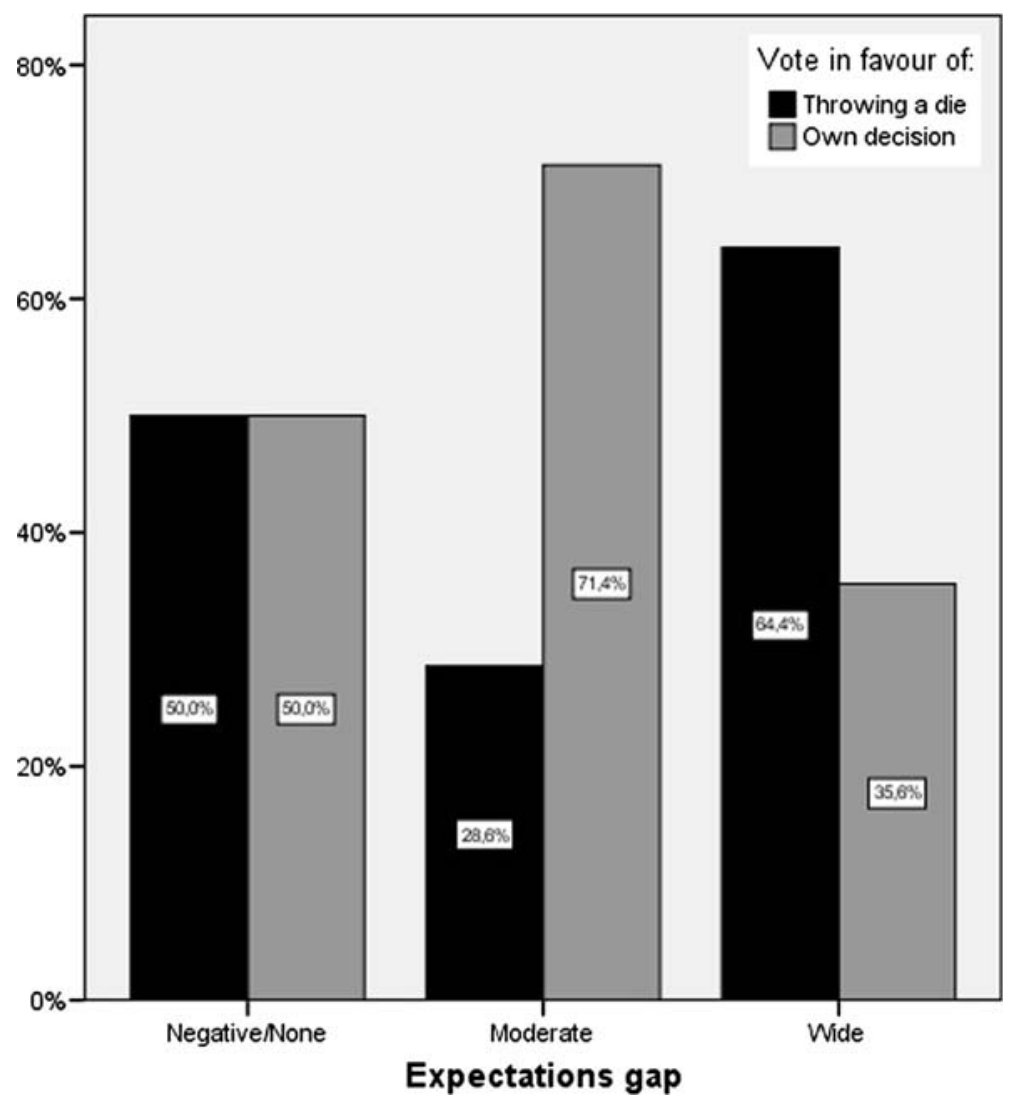

Fig. 2 Voting behaviour by size of expectation gap 
were atypically high or low in certain stages. Let us therefore define a measure $\alpha^{k}$ that captures the relative attractiveness of the non-agency and agency condition in terms of payoff generation for participants in group $k$ :

$$
\alpha^{k}=\left(2 \times Y_{N}^{k} / 3\right) / Y_{A 3}^{k} .
$$

The assumption is that participants compare the average payoff that the group managed to earn over the three rounds in the first, or non-agency $(N)$, stage to the payoff earned in the third round of the second stage (A3), with a correction for the difference in number of extra rounds on offer $(2: 1)$. The motivation for taking the payoff from the last round rather than the average payoff over all three rounds in the second stage is the fact that considerable learning was observed from one round to the other. It took most groups one or sometimes two rounds to settle on the optimal group strategy of putting only one coin. Once they experience the high payoff from this strategy, it is unlikely that they revert to a sub-optimal strategy in an extra round. Groups that managed to coordinate on the optimal solution from the first agency round onwards, for instance, largely adhered to it throughout the two subsequent rounds. On the other extreme, four groups failed to come close to the optimal solution even after three rounds. Hence, there seems no reason for the members of these groups to expect much higher payoffs from agency in an additional round. While $\alpha^{k}$ is very close to 1 (equal degree of attractiveness) on average over all groups ( $\mu=0.99$; $\sigma=0.14$ ), its value ranges from 0.67 to 1.22 for individual groups. We will therefore include $\alpha^{k}$ as a control variable when performing a logistic regression on the likelihood that an individual participant votes in favour of agency.

A second factor that we like to control for is one that may increase an individual's valuation of agency but is unrelated to expectations, namely one's own contribution to the total group payoff in stage II, which we denote by $\delta^{i k}$ as follows:

$$
\delta^{i k}=\left(y_{A}\right)^{i} /\left(Y_{A}\right)^{k} \quad \text { where } Y=\sum_{i} y .
$$

This expression captures the idea that exercising agency feels more rewarding in case it turns out that it is your decision that actually matters for the group. The link between high payoffs and enhanced decision-making power is less salient otherwise. About $42 \%$ of the participants did not make any contribution to the group payoff in Stage II, whereas others contributed up to $30-40 \%$ of the total.

Table 2 reports on the logistic regression results performed to explain the voting behaviour in the experiment, which broadly confirm the univariate picture observed in Fig. 2. Participants who experienced a moderate (wide) expectation gap are significantly more (less) likely to vote in favour of agency compared to those who did not face an expectation shortfall (omitted category). The variables $\alpha$ and $\delta$ have the expected sign, but are not significant. Finally, a dummy variable was included to analyse whether participants from Puri attach more value to agency than Balangir residents, given that the empowerment indicators discussed in Sect. 2 suggest more decision-making power in the household for women in Puri. While the sign of the coefficient points in this direction, the effect is rather weak.

It is interesting to observe that the most pronounced difference in the valuation of agency is not between those to the left and right of the $g=0$ line in Fig. 1, but between the groups with moderate and wide expectation gaps. If we run the same logistic regression leaving out those with $g \leq 0$, the difference in the probability of voting in favour or against agency between the two groups is significant at the $1 \%$ level. According to the odds ratio 
Table 2 Logistic regression: probability of casting vote in favour of agency

*Indicates significance at $10 \%$

\begin{tabular}{lllll}
\hline Variable & $\begin{array}{l}\text { Parameter } \\
\text { estimate }\end{array}$ & $\begin{array}{l}\text { Odds ratio } \\
\text { estimate }\end{array}$ & $\begin{array}{l}\text { Wald } \\
\text { chi-square }\end{array}$ & $P$ value \\
\hline $\begin{array}{l}\text { Expectation gap } \\
\text { Moderate }\end{array}$ & $0.85^{*}$ & 2.3 & 2.89 & 0.089 \\
$\quad$ Wide & $-0.69^{*}$ & 0.5 & 2.96 & 0.085 \\
$\alpha^{k}$ & -0.42 & 1.6 & 0.11 & 0.739 \\
$\delta^{i k}$ & 1.89 & 6.6 & 1.18 & 0.277 \\
Puri & 0.50 & 1.6 & 1.99 & 0.158 \\
Constant & 0.09 & 1.1 & 0.01 & 0.941 \\
$n=156$ & & & \\
Nagelkerke $R^{2}=0.13$ & & & \\
$\chi^{2}=15.7(P<0.01)$ & & & \\
\hline
\end{tabular}

estimate, a participant that experienced a moderate gap is five times more likely to vote in favour of retaining agency than her counterpart with a wide gap. If the low valuation of agency in the latter group is the result of unmet expectations, we should also expect lower reported levels of satisfaction after stage II for this group, especially compared to those with a moderate gap, since they show the starkest disparity in voting behaviour. When analyzing the role of SWB, therefore, we concentrate on a comparison between these two groups.

A complication with regard to detecting potential differences in reported SWB is that participants' satisfaction levels were generally high after the second stage as a result of a marked increase in payoffs between stages I and II. None of the participants indicated to be 'not at all satisfied' and only $10 \%$ was reportedly 'not so satisfied' with the achieved payoff. Nonetheless, the likelihood that a participant was 'very satisfied' (as opposed to 'somewhat satisfied' or an occasional 'not so satisfied') might be informative. Within the group with a moderate gap, the proportion of respondents indicating that they were 'very satisfied' with the outcome of the second stage was $43 \%$. The corresponding proportion in the group with a wide disparity between expectation and achievement was only $26 \%$. This difference in satisfaction is significant at $10 \%\left(\chi^{2}=3.11, P=0.08\right)$, which hints at the presence of a factor holding back satisfaction levels in the latter group.

Let us check whether this result holds up when we introduce a set of control variables that may affect participants' degree of satisfaction with $Y_{\mathrm{A}}$. The most obvious factors to include are $Y_{\mathrm{A}}$ itself as well as $Y_{\mathrm{N}}$, which are expected to show opposite signs, because participants' SWB is likely to respond to the increase in $Y$ from stage I to II. In addition, the level of satisfaction reported after stage I has been taken up in the regression in order to capture interpersonal differences in the marginal utility of additional income. Women from poorer households can be expected to derive more satisfaction from a certain money gain than women from not-so-poor families, for instance. Finally, possible 'warm glow' effects from contributing to the group payoff should be controlled for, which motivates the inclusion of $\left(\delta_{\mathrm{A}}-\delta_{\mathrm{N}}\right)^{i k}$.

The logistic regression results in Table 3 substantiate the claim that experiencing a wide expectation gap-compared to a modest one-tends to imply a lower level of satisfaction. The coefficient for the dummy representing this group is negative and significant. As expected, $Y_{\mathrm{A}}$ enters the regression positively, while the opposite is true for $Y_{\mathrm{N}}$. The other two control variables fail to show a significant impact. 
Table 3 Logistic regression: probability of being "very satisfied" with $Y_{A}$
$* * *, * *$ and * indicate significance at 1, 5 and $10 \%$, respectively

\begin{tabular}{lclll}
\hline Variable & $\begin{array}{l}\text { Parameter } \\
\text { estimate }\end{array}$ & $\begin{array}{l}\text { Odds ratio } \\
\text { estimate }\end{array}$ & $\begin{array}{l}\text { Wald } \\
\text { chi-square }\end{array}$ & $P$ value \\
\hline Wide expectation gap & $-0.85^{*}$ & 0.4 & 3.16 & 0.075 \\
$Y_{A}$ & $0.12^{*}$ & 1.0 & 3.00 & 0.084 \\
$Y_{N}$ & $-0.56^{* * *}$ & 0.9 & 8.36 & 0.004 \\
Degree of reported & 0.37 & 1.5 & 0.83 & 0.361 \\
$\quad$ satisfaction with $Y_{N}$ & & & & \\
$\left(\delta_{A}-\delta_{N}\right)^{i k}$ & 1.02 & 2.8 & 0.44 & 0.506 \\
Constant & $3.11^{* *}$ & 1.5 & 4.23 & 0.040 \\
$n=108$ & & & & \\
Nagelkerke $R^{2}=0.19$ & & & & \\
$\chi^{2}=15.3(P<0.01)$ & & & & \\
\hline
\end{tabular}

\section{An Aspiration-based Interpretation}

In this section we present a tentative explanation for the result that participants experiencing a modest expectation gap seem particularly eager to continue to make their own decisions, despite the fact that achievements did not fully meet expectations. The explanation is based on the notion of aspirations level, a well-established concept in psychology that refers to "a subjectively established goal for achievement" (Karlsson et al. 2004, p. 755). This in turn acts as a crucial reference point for the level of satisfaction with actual achievements (McBride 2007).

Early empirical work on aspirations (Irwin 1944) established that aspiration levels are positively correlated with expectation levels, where the former tend to exceed the latter. This is also reflected in Kahneman's (2000) definition of an aspiration level as "a value on a scale of achievement or attainment that lies somewhere between realistic expectation and reasonable hope" (p. 687). Studies on aspirations have paid little attention to expectations as a determinant of aspirations, however. The literature has mainly focussed on two other determinants, i.e., the impact of past outcomes through adaptation and that of outcomes achieved by others through social comparisons. ${ }^{8}$ A notable exception is a recent experimental study by McBride (2007), who tests the importance of expectations relative to that of past outcomes and outcomes of referent others for how individuals set aspirations. His experiment reveals that "the largest factor in payoff aspirations is the subject's expected payment, which comprises the primary factor a subject considers when deciding whether or not her achievement is satisfactory or dissatisfactory" (p. 34). Occasionally the importance of expectations is implicitly acknowledged in the happiness literature. For instance, Van Praag and Ferrer-i-Carbonell (2004, p. 79) observe that "[f]or most people expectations will define a too high aspiration level and this generates disappointment". It may therefore be the case that the relevant factor in our experiment is in fact that of aspiration gap rather than expectation gap as such, although the latter is an important cause of the former.

Ray (2006) has formulated an interesting theory on how aspiration gaps affect people's future-oriented behaviour. The main idea is that if the gap is not too large, an individual has a strong impetus to close it in the near future and is therefore willing to exert costly effort today. On the other hand, if the aspiration gap is sufficiently wide, efforts to invest in attaining the aspiration level in the future become minimal, since "the overall journey is

\footnotetext{
${ }^{8}$ See Stutzer (2004) for an overview.
} 
too long, and therefore not worth undertaking in the first place" (p. 412). He refers to this as "the curse of frustrated aspirations" or aspiration failure. According to Ray, those who do not experience an aspiration gap also suffer from aspiration failure in a sense, since there is little incentive for this group either to invest in raising outcomes in the future. This suggested inverted U-shape relation between aspiration gap and the level of incentive to attain one's aspired level in the future through exerting additional effort is consistent with Kahneman and Tversky's (1979) prospect theory. The $S$-shaped value function in prospect theory exhibits low marginal utility from improvements in outcomes in the region far below the reference point, high marginal utility when approaching the reference point and low marginal utility again above the reference point. The curse of frustrated aspirations, which causes individuals with wide gaps to abandon one's aspirations altogether and triggers behaviour characterized by minimal effort towards generating future improvements, is known in psychology as "the starting problem" (Heath et al. 1999, p. 89).

Although admittedly somewhat speculative, we believe that Ray's theory offers a plausible explanation of the observed voting behaviour in our field experiment or, at least, that similar processes are at work. Participants whose expectations were too optimistic, but not dramatically so, may have a lot to gain in terms of satisfaction from making a new attempt at attaining the aspired payoff level. This challenge can only be undertaken when voting in favour of remaining with agency. By contrast, incentives to do so may be seriously flawed for both those with a negative gap as well as those with a wide positive gap, since the experience in stage II proved either insufficiently challenging or too discouraging.

\section{Conclusion}

The development literature tends to portray the enhancement of poor people's capabilities as a more virtuous objective than trying to improve their subjective well-being. This paper started out from the premise that it is risky to ignore subjective well-being even in case one decides to embrace the capability approach, if not only because negative changes in subjective wellbeing may thwart the process of building capabilities, such as signalled by Biswas-Diener (2002) in the case of empowerment. In particular, this paper has explored one concrete mechanism that is put forward in the literature as potentially responsible for an SWB failure triggering disempowering attitudes among poor women, which is the presence of unrealistic expectations.

Our field experiment with a number of women self-help groups in India provides evidence that this suggestion in the literature may be warranted. It is observed in the game that if the gap between expectations and achievements becomes too wide, the valuation of agency tends to go down. Moderate expectation shortfalls on the other hand seem to have the opposite effect and foster a stronger degree of commitment to future empowerment. The validity of these results is subject to potential caveats of the experimental design, however.

A drawback of the experiment is that individuals' risk attitudes may have played an interfering role. Relatively risk-loving individuals obtain more intrinsic utility from the game of chance (stage I) for a given payoff than more risk-averse types and can therefore be expected to be more inclined to vote in favour of 'throwing a die'. If the risk-loving (risk-averse) types are concentrated -perhaps due to some overlapping character trait- in the group with wide (moderate) expectation gap, our results could be partly driven by differences in risk attitudes. While we have no direct information on risk attitudes, we do 
not find a significant difference in satisfaction levels after the risky stage (I) between the groups with a moderate and wide gap (Mann-Whitney test; $z=-1.15, P=0.25$ ). This holds even after controlling for $Y_{N}$ and $\delta_{N}$. In addition, it should be borne in mind that the game with agency (stage II) entails substantial risk as well, as the behaviour of fellow group members is uncertain and deviating players can cause a sizeable drop in payoff. A related caveat concerns the possibility that participants enjoyed playing the game, regardless of this being governed by chance or own agency, and therefore more inclined to vote for two extra rounds (non-agency) rather than one (agency). It is not clear, however, why this preference should be systematically correlated with the size of one's expectation gap.

More fundamentally, one might entertain doubts as to whether setting expectations with respect to outcomes in real life is subject to similar processes as doing so in the case of a simple game, since the stakes are much lower in the latter. We feel that this is a legitimate question that requires further study, but the experiment conducted by McBride (2007) on aspirations is encouraging in this respect. He finds that "aspirations operate even with respect to relatively small experiment payoffs" (pp. 5-6). Despite the necessary reservations, we believe our exploratory results warrant more work on the effect of expectations on the success of development interventions and their potential to create virtuous cycles of empowerment. Preferably, this should be studies of a longitudinal character that monitor beneficiaries over a longer period. In addition, such studies should ideally be able to include personality dimensions that we might expect to be systematically related to a person's valuation of agency, such as risk attitude and time preferences, individual modernity, and levels of self-esteem and self-efficacy. If such more rigorous studies would corroborate our results, interesting implications are to be drawn for development interventions, as till now their design "rarely addresses subjective factors such as the gap between expectation and achievement from program participation" (Ahmed et al. 2001, p. 1962). The lack of attention for these factors entails the risk of swelling the ranks of 'frustrated achievers', at least in the short and medium run. ${ }^{9}$

With regard to the current dispute between the supporters of the capability and happiness approach to well-being, the paper purports to stress that the choice for either the cultivation of capabilities or the promotion of happiness unlikely implies a conventional trade-off. Embracing one of these as the prime aim does not simply require a willingness to accept a possible negative impact on the other. The capability supporters, for instance, should not only acknowledge the risk of a loss in subjective well-being in the process of cultivating capabilities, but also the risk that if this loss exceeds some critical level, it may undermine the process itself.

Acknowledgments I am indebted to Anouka van Eerdewijk for extensive discussion and helpful comments as well as to participants in the 'Happiness and Capability: Measurement, Theory and Policy' workshop, August 2008, Ravenstein, the Netherlands. I also like to thank Debyaranjan Sahu, Braja Sundar Das and Rajeswari Patna for their assistance in the field. Support from Cordaid and its local partner organization in Orissa is greatly acknowledged.

Open Access This article is distributed under the terms of the Creative Commons Attribution Noncommercial License which permits any noncommercial use, distribution, and reproduction in any medium, provided the original author(s) and source are credited.

\footnotetext{
9 Graham and Pettinato (2002) coin the label of "frustrated achievers" to describe certain sections of the Peruvian population that enjoyed a strong improvement in income, but nevertheless reported lower satisfaction with their economic situation, allegedly due to an opening up of their aspirations window.
} 


\section{Appendix: Protocol of 'Empowerment Game' (original instructions in Oriya)}

Welcome to all of you. The game that we will be playing for the next hour is about making decisions that not only affect yourself, but affect others as well. As members of a self-help group, you often take such type of decisions, for example when you decide to contribute to group savings or whether to take out a loan from the savings account. Please note that the game, which we are about to explain, is not a test, so there is no wrong or right thing to do. However, it is important that you think about your decisions carefully, because what you decide affects the entire group. In the game you will earn a certain amount of money as a group. The rupees that you earn will go into the group's savings account (a bowl clearly marked "group savings account" is shown to participants). Each of you will be able to benefit equally from the money that you manage to win, regardless of who 'earns' it in the game. The money is provided by an organization in the Netherlands, so you do not play with your own money and therefore cannot lose anything.

The game works as follows. Each of you has received a small purse. In the purse you will find 7 coins. Each of you has coins of a different colour (green, red, black, white, blue etc.). You will be asked to put a certain number of your coins in the pot. When all of you have done so, we will thoroughly mix all the coins in the pot and blindly draw two coins from it. If one of your coins is taken out, you will make a contribution to the group savings account. How many rupees you earn for the group depends on the number of coins that you kept (i.e., that you did not put in the pot). The more coins you kept, the higher the contribution to the savings account. The rules of the game are shown in Table 4.

Hence, if you put more coins in the pot, the higher your chance that you will earn something for the group. At the same time, if you put less coins (and keep more), you can earn larger amounts of money. Note that if the second coin that is drawn from the pot is of the same colour as the first one, it will be disregarded and a third one will be drawn instead (if necessary drawing continues until we have two coins of a different colour).

At the end of the game session we will count how many rupees you have earned in total and hand the money over in cash to the group's secretary.

First we will play 3 rounds of this game in which you have little influence over how many coins to keep. Each of you rolls a die and the number that comes up is the number of coins that will go into the pot. Let us see how it works. This is not yet for real. (practice rounds with die).

After playing 3 rounds like this, we take away the die and you will be able to make your own choice concerning how many coins to put in the pot and how many to keep. We will play another 3 rounds without die. The only thing to remember is that you cannot put all seven coins (keep at least one) and not keep all seven (put at least one). Please keep in mind that you decide on how many coins to keep without discussing this with your

Table 4 The rules of the empowerment game

\begin{tabular}{ll}
\hline Number of coins kept & $\begin{array}{l}\text { Contribution to group's savings } \\
\text { account (in Rs.) }\end{array}$ \\
\hline 1 & 5 \\
2 & 10 \\
3 & 15 \\
4 & 20 \\
5 & 25 \\
6 & 30 \\
\hline
\end{tabular}


neighbour. It is your own individual decision. Let us first try this out as well, without real money. (practice rounds without die).

Now we are going to play for real. First, we will play with the die for 3 rounds.

(Play out 3 rounds with participants rolling a die. Each round two coins are drawn randomly from the pot in public, the colour of the coins is announced as well as the respective contribution to the savings account according to the rules of the game. The rupees earned per round are added to the symbolic 'group savings account'. The total payoff over the 3 rounds is calculated and communicated to the participants).

As a group you earned Rs. $X$ in total over these 3 rounds.

Before giving you real decision power, I would like to know two things from each of you individually.

1. How satisfied are you with the amount that you managed to earn as a group over the first 3 rounds? (Elicit satisfaction level of each participant. Possible responses include "not at all satisfied", "not so satisfied", "rather satisfied" and "very satisfied").

2. How many rupees do you expect you will manage to earn as a group in the next 3 rounds, where you can freely decide how many coins to keep? The person whose expectation comes closest to the amount that you actually earn will receive a small gift. Please do not discuss your expectation with other group members. (Elicit expectations regarding payoff).

(Play out 3 rounds with participants deciding freely on number of coins to keep. Otherwise same procedure as in rounds with die).

As a group you earned Rs. $X$ in total over these 3 rounds.

Again I would like you to indicate how satisfied you are with the amount of money that you managed to earn as a group over the past 3 rounds. [Elicit new satisfaction level of each participant (same response categories)].

Now let us check who has won the small prize for making the best guess regarding the total earnings over the past 3 rounds without die. (Announce person whose expected payoff was closest to actual payoff and hand over small gift).

To conclude the game, we offer you the following choice. Either we play one extra game in which you can freely choose the number of coins that you would like to keep (i.e., without die), or play two extra games by rolling a die, as we did before. You decide by voting. Each of you receives two voting cards and your purse is the ballot box. If you prefer to play one extra round without die, you put card 2 in your purse, together with one of your coins, and put card 1 head-down on the floor in front of you. Alternatively, if you prefer to play two extra rounds with die, you put card 1 in your purse, together with one of your coins, and put card 2 head-down on the floor. Once you have cast your vote, we collect the purses as well as the cards on the floor. All cards in the purses will be counted. If there are more cards 1 , we will play two extra rounds with die, whereas if there are more cards 2, we will play one extra round without die. In case of a tie, a coin will be tossed to decide for one or the other. Please be sure that others will not find out how you voted.

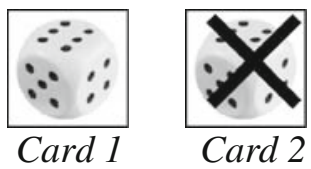

[Announce majority decision and play out corresponding round(s)] 
In total, as a group, you managed to add Rs. $X$ in this final round (or final rounds in case majority vote cast in favour of die). This makes in total, together with all the previous rounds we played, $X$ Rupees. We will add this amount to the group's savings account. (Hand over total payoff to group's secretary). Congratulations and thank you very much for your participation!

\section{References}

Ahmed, S. M., Chowdhury, M., \& Bhuiya, A. (2001). Micro-credit and emotional well-being: Experience of poor rural women from Matlab, Bangladesh. World Development, 29, 1957-1966. doi:10.1016/ S0305-750X(01)00069-9.

Alsop, R., Bertelsen, M. F., \& Holland, J. (2006). Empowerment in practice: From analysis to implementation. Washington: World Bank.

Barr, A., \& Clark, D. A. (2007). A multidimensional analysis of adaptation in a developing country context. CSAE Working Paper no. 17, Centre for the Study of African Economies, Department of Economics, University of Oxford.

Biswas-Diener, R., \& Diener, E. (2001). Making the best of a bad situation: Satisfaction in the slums of Calcutta. Social Indicators Research, 55, 329-352.

Clark, D. A. (2007). Adaptation, poverty and well-being: Some issues and observations with special reference to the capability approach and development studies. GPRG Working Paper no. 81, Global Poverty Research Group, Department of Economics, University of Oxford.

Diener, E., \& Biswas-Diener, R. (2005). Psychological empowerment and subjective well-being. In D. Narayan (Ed.), Measuring empowerment: Cross-disciplinary perspectives (pp. 125-140). Washington, DC: World Bank.

Frederick, S., \& Loewenstein, G. (1999). Hedonic adaptation. In D. Kahneman, E. Diener, \& N. Schwarz (Eds.), Well-being: The foundations of hedonic psychology (pp. 302-373). New York: Russell Sage Foundation.

Government of Orissa. (2004). Orissa Human Development Report 2004. Department of Planning and Coordination, Government of Orissa, Bhubaneswar.

Graham, C., \& Pettinato, S. (2002). Frustrated achievers: Winners, losers and subjective well-being in new market economies. The Journal of Development Studies, 38, 100-140. doi:10.1080/002203804 12331322431.

Guillen-Royo, M. (2008). Consumption and subjective wellbeing: Exploring basic needs, social comparison, social integration and hedonism in Peru. Social Indicators Research, in press. doi:10.1007/ s1120500892481.

Heath, C., Larrick, R. P., \& Wu, G. (1999). Goals as reference points. Cognitive Psychology, 38, 79-109. doi:10.1006/cogp.1998.0708.

Irwin, F. W. (1944). The realism of expectations. Psychological Review, 51, 120-126. doi:10.1037/ h0061743.

Jakimow, T., \& Kilby, P. (2006). Empowering women: A critique on the blueprint for self-help groups in India. Indian Journal of Gender Studies, 13, 375-400. doi:10.1177/097152150601300303.

Kabeer, N. (1999). Resources, agency, achievements: Reflections on the measurement of women's empowerment. Development and Change, 30, 435-464. doi:10.1111/1467-7660.00125.

Kabeer, N. (2001). Conflict over credit: Re-evaluating the empowerment potential of loans to women in rural Bangladesh. World Development, 29, 63-84. doi:10.1016/S0305-750X(00)00081-4.

Kahneman, D. (2000). Experienced utility and objective happiness: A moment-based approach. In D. Kahneman \& A. Tversky (Eds.), Choices, values and frames (pp. 673-692). New York: Cambridge University Press and Russell Sage Foundation.

Kahneman, D., \& Tversky, A. (1979). Prospect theory: An analysis of decision under risk. Econometrica, 47, 263-291. doi:10.2307/1914185.

Karlsson, N., Dellgran, P., Klingander, B., \& Gärling, T. (2004). Household consumption: Influences of aspiration level, social comparison, and money management. Journal of Economic Psychology, 25, $735-769$.

McBride, M. (2007). Money, happiness and aspirations: An experimental study. Working Paper 060721, Department of Economics, University of California-Irvine.

Omorodion, F. (2007). Rural women's experience of micro-credit schemes in Nigeria: Case study of Esan women. Journal of Asian and African Studies, 42, 479-494. doi:10.1177/0021909607083216. 
Ray, D. (2006). Aspirations, poverty and economic change. In A. V. Banerjee, R. Bénabou, \& D. Mookherjee (Eds.), Understanding poverty (pp. 409-421). New York: Oxford University Press.

Rojas, M. (2008). Experienced poverty and income poverty in Mexico: A subjective well-being approach. World Development, 36, 1078-1093. doi:10.1016/j.worlddev.2007.10.005.

Rowlands, J. (1997). Questioning empowerment: Working with women in Honduras. Oxford: Oxfam Publishing.

Stern, N., Dethier, J. J., \& Rogers, F. H. (2005). Growth and empowerment: Making development happen. Cambridge, MA: MIT Press.

Stutzer, A. (2004). The role of income aspirations in individual happiness. Journal of Economic Behavior \& Organization, 45, 89-109. doi:10.1016/j.jebo.2003.04.003.

Van Praag, B. M. S., \& Ferrer-i-Carbonell, A. (2004). Happiness quantified: A satisfaction calculus approach. Oxford: Oxford University Press. 